Article

\title{
A UN SDGs-Based Sustainability Evaluation Framework for Globally Important Agricultural Heritage Systems (GIAHS): A Case Study on the Kuaijishan Ancient Chinese Torreya Community
}

\author{
Wen Zhao ${ }^{1,2}$, Siming Wang ${ }^{1, *}$, Yongxun Zhang ${ }^{3, *}$, Ming Xu ${ }^{2, *}$, Hongkai Qie ${ }^{1}$, Yong Lu ${ }^{1}$, Hanning Lu ${ }^{2}$ \\ and Ran An ${ }^{2}$ \\ 1 Institution of Chinese Agricultural Civilization, Nanjing Agricultural University, Nanjing 210095, China; \\ zhaowen@agri.gov.cn (W.Z.); qiehongkai@163.com (H.Q.); luyong@njau.edu.cn (Y.L.) \\ 2 Center of International Cooperation Service, Ministry of Agriculture and Rural Affairs, Beijing 100125, China; \\ luhanning@agri.gov.cn (H.L.); anran@agri.gov.cn (R.A.) \\ 3 Institute of Agricultural Economics and Development, Chinese Academy of Agricultural Sciences, \\ Beijing 100081, China \\ * Correspondence: icac@njau.edu.cn (S.W.); zhangyongxun@caas.cn (Y.Z.); xuming@agri.gov.cn (M.X.); \\ Tel.: +86-010-8210-6193 (Y.Z.)
}

check for updates

Citation: Zhao, W.; Wang, S.; Zhang, Y.; Xu, M.; Qie, H.; Lu, Y.; Lu, H.; An, R. A UN SDGs-Based Sustainability Evaluation Framework for Globally Important Agricultural Heritage Systems (GIAHS): A Case Study on the Kuaijishan Ancient Chinese Torreya Community. Sustainability 2021, 13, 9957. https://doi.org/ $10.3390 /$ su13179957

Academic Editors: Luis Jesús Belmonte-Ureña and Teodor Rusu

Received: 8 July 2021

Accepted: 1 September 2021

Published: 5 September 2021

Publisher's Note: MDPI stays neutral with regard to jurisdictional claims in published maps and institutional affiliations.

Copyright: (c) 2021 by the authors. Licensee MDPI, Basel, Switzerland. This article is an open access article distributed under the terms and conditions of the Creative Commons Attribution (CC BY) license (https:// creativecommons.org/licenses/by/ $4.0 /)$.
Abstract: The Food and Agriculture Organization of the United Nations (FAO) launched the conservation initiative of the Globally Important Agricultural Heritage Systems (GIAHS) in 2002, providing a new solution to current global problems such as widening gap between rich and poor, environmental pollution, biodiversity destruction and degradation of agro-ecological functions. However, since the implementation of GIAHS, few studies have evaluated the role of GIAHS in regional sustainable development. To fill this research gap, this paper attempts to build an evaluation index system that integrates economic, social and environmental sustainability by matching the 169 subgoals and 232 indices of the UN Sustainable Development Goals (SDGs) with five FAO-GIAHS selection criteria and selecting the indices. The index weights are determined through Delphi method (expert scoring) and Analytic Hierarchy Process (AHP). Then the GIAHS site of the Kuaijishan Ancient Chinese Torreya Community in Shaoxing City, Zhejiang Province is taken as an example for evaluation to enhance the empirical study. The results show that the comprehensive score for this heritage site is 77.90 points, of which economic, social and environmental sustainability scores $88.27,86.12$ and 69.71 points respectively, showing a descending trend. Thus, ecological protection of the Kuaijishan Ancient Chinese Torreya Community should be strengthened and be given prominence in the future. As for the contribution to further research, this SDGs-based GIAHS sustainability evaluation framework can serve as an important guide for assessing the approaches and effects of GIAHS in promoting the achievement of the SDGs. It can also be used for future international GIAHS sustainability assessment and comparison and provide a basis for adjusting the development model of GIAHS sites.

Keywords: United Nations Sustainable Development Goals (SDGs); GIAHS; evaluation index system; sustainability evaluation

\section{Introduction}

At the Millennium Summit in September 2000, 189 heads of state and representatives of the UN member nations signed the United Nations Millennium Declaration, which unanimously adopted the 8 general goals, 21 concrete targets and 60 indices of the Millennium Development Goals (MDGs). After more than a decade of international cooperation on development, in September 2015, the UN established Sustainable Development Goals (SDGs) as a programmatic document to guide world development policies and the use of funds 
from 2015 to 2030 for global poverty eradication as well as sustainable social, economic and environmental development. Scholars around the world have positively responded to the SDGs and focused on cities, energy, health, climate and poverty elimination [1-3]. The UN Sustainable Development Solutions Network [4] evaluates the SDGs baseline of 149 countries using the World Bank Database and referring to Bertelsmann Stiftung Dashboards, which provides an important reference for the comparison of sustainable development in different regions in the future. Chen et al. have completed a quantitative evaluation of the implementation of the 2030 Agenda for Sustainable Development in Deqing County, Zhejiang Province, using a comprehensive method combining statistics and geographical information. This is the first quantitative evaluation report on the practice of the 2030 SDGs in China [5]. However, although food production systems, traditional technologies and biodiversity are abundant in rural and agricultural fields, few researchers have paid attention to the SDGs [6].

In response to the loss of traditional technologies, loss of biodiversity, degradation of agro-ecosystems and unsustainable agricultural development caused by the rapid urbanization, industrialization and application of modern technologies in agriculture, the FAO also launched the initiative for Globally Important Agricultural Heritage Systems (GIAHS) conservation at the World Summit on Sustainable Development in Johannesburg in August 2002 and implemented the GIAHS Dynamic Conservation and Adaptive Management Project with the support of the Global Environment Facility (GEF). It aims to establish a conservation system for GIAHS and their relevant landscapes, biodiversity, knowledge and culture, and to gain recognition and protection worldwide, providing technical support for sustainable agricultural and rural development. As a global program to find wisdom for sustainable human development from traditional farming civilizations, the GIAHS project has been widely recognized by the international community for nearly 20 years since its launch, attracting more and more countries to GIAHS protection. However, the FAO has not yet put forward the requirements and guidance on GIAHS monitoring and evaluation since its implementation, and the existing literature is mainly on the exploration by Chinese, Japanese and Korean scholars to establish national GIAHS evaluation index systems and monitoring systems as well as to sum up the monitoring methods [7-10]. The theory of sustainable development was first proposed at the World Commission on Environment and Development in 1987. Goodland [11] believes that sustainable development is a process of change in which resource utilization, investment orientation, technological progress and policy adjustment are coordinated and continuously enhance the potential to meet human needs now and in the future. Therefore, it should be evaluated from social, economic and environmental views. The GIAHS project is an important initiative to achieve the SDGs, but there are few scholars evaluating the role of GIAHS in promoting sustainable regional development under the UN SDGs framework [12]. Therefore, this paper tries to build an integrated weighted index system that applies the SDGs indices to GIAHS evaluation and validates it through an empirical study on the GIAHS site of the Ancient Chinese Torreya Community in Shaoxing City, Zhejiang Province. The system is also applicable to sustainability evaluation, management and protection of other countries and regions.

The following section of this text includes four sections: the first section is RESEARCH METHOD, which analyzes the correlation between GIAHS selection criteria and 17 SDGs and constructs an evaluation index system through expert scoring method; the second section is CASE STUDY, taking the Kuaijishan Ancient Chinese Torreya Community in Shaoxing City, Zhejiang Province as a research object and assessing it sustainability; the third section is DISCUSSION, analyzing this study's the reasonability of results, academic contributions and existing shortcomings; the last section is CONCLUSIONS AND RECOMMENDATIONS, stating the main findings from this study and proposing recommendations for sustainability evaluation tasks of GIAHS in the future. 


\section{Research Methods}

\subsection{Analysis of the Correlation between GIAHS Selection Criteria and 17 SDGs}

There are five criteria for identifying GIAHS: (1) food and livelihood security, (2) agrobiodiversity, (3) local and traditional knowledge systems, (4) cultures, value systems and social organizations as well as (5) landscapes and seascapes features [13]. All of these official criteria are closely related to the UN SDGs. For example, China's Rice Fish Culture was identified as a GIAHS site in 2005, and after 10 years of development, the price of rice produced in the region has doubled and tourism revenues have increased in Qingtian County. Obviously, the GIAHS conservation is the implementation of SDG8. Several GIAHS sites in China have adopted new technologies and cooperated with the private sector to promote products of the heritage sites and create jobs, achieving SDG 8. The United Republic of Tanzania's GIAHS site has helped raise women's voice and involved them in the decision-making process in their villages, promoting gender equality (SDG 5). The specific correspondence is shown in Figure 1. It should be noted that based on the literature and explanation of indices, the correspondence is not absolute authoritative, which needs to be improved in the follow-up study.

Criterion 1: Food and livelihood security. Sustainable agricultural systems for food production and economic activities for rural livelihoods and decent jobs in GIAHS sites are linked to the SDG1 and SDG8 [14]; and encouraging the sustainable consumption and food production of GIAHS is relevant to the SDG12 [15].

Criterion 2: Agro-biodiversity. Rich agro-biodiversity contributes to hunger alleviation, climate change adaptation and conservation of biodiversity in surrounding terrestrial and aquatic ecosystems, which is associated with the SDG6, SDG11 and SDG15 [16].

Criterion 3: Local and traditional knowledge systems. The sustainable use of natural resources with the help of traditional knowledge and practices can also contribute to conserving terrestrial and aquatic environment and combating climate change, which is related to the SDG13 [17].

Criterion 4: Cultures, value systems and social organizations. Equity in the use of and access to natural resources can be promoted by recognizing the role of women in maintaining cultural and social values, which is linked to the SDG3, SDG4, SDG5, SDG11 and SDG16; and partnerships between rural and urban areas can be built by taking an innovative and dynamic integrated approach to conservation, which is relevant to the SDG9, SDG16 and SDG17 [6].

Criterion 5: Landscapes and seascapes features. The ecological resilience of GIAHS ensures the supply of clean water and protects habitats for terrestrial and aquatic organisms, which is linked to the SDG6 and SDG15 [18].

GIAHS identification and evaluation are highly relevant and therefore can be conducted in the same GIAHS in different years according to the five criteria [19]. When a traditional agricultural system is designated by FAO as GIAHS, its corresponding indices will be continually followed up and assessed for a comprehensive evaluation. As shown in Figure 2, the SDGs and their concrete indices are well matched with the five GIAHS certification criteria, which will guide GIAHS evaluation and make the indices more comprehensive and authoritative. Due to the many factors involved in the SDGs and their indices and the complex technical process, the research on the SDGs faces many challenges such as the scientific understanding of the global index system, integration and processing of massive spatial and temporal data, index calculation taking geospatial information into account, fact-based analysis and evaluation of the SDGs, comprehensive interdisciplinary analysis as well as communication and coordination among multiple institutions [20]. The research and application of the SDGs in China and beyond are still at the stage of conceptual design, methodological exploration as well as single-index and small-scale pilot. 


\begin{tabular}{|c|c|c|c|}
\hline \multicolumn{2}{|c|}{ The 5 GIAHS Criterion } & \multicolumn{2}{|r|}{ The 17 UN Sustainable Development Goals } \\
\hline \multirow{3}{*}{ Criterion 1} & \multirow{3}{*}{$\begin{array}{l}\text { Food and livelihood } \\
\text { security }\end{array}$} & SDG1 & End poverty in all its forms everywhere \\
\hline & & SDG8 & $\begin{array}{l}\text { Promote sustained, inclusive and sustainable economic growth, full and } \\
\text { productive employment and decent work for all }\end{array}$ \\
\hline & & SDG12 & Ensure sustainable consumption and production patterns \\
\hline \multirow[b]{3}{*}{ Criterion 2} & \multirow[b]{3}{*}{ Agro-biodiversity } & SDG6 & Ensure availability and sustainable management of water and sanitation for all \\
\hline & & SDG11 & Make cities and human settlements inclusive, safe, resilient and sustainable \\
\hline & & SDG15 & $\begin{array}{c}\text { Protect, restore and promote sustainable use of terrestrial ecosystems, } \\
\text { sustainably manage forests, combat desertification, halt and reverse land } \\
\text { degradation and halt biodiversity loss }\end{array}$ \\
\hline Criterion 3 & $\begin{array}{l}\text { Local and traditional } \\
\text { knowledge systems }\end{array}$ & SDG13 & Take urgent action to combat climate change and its impacts \\
\hline \multirow{7}{*}{ Criterion 4} & \multirow{7}{*}{$\begin{array}{l}\text { Cultures, value } \\
\text { systems and social } \\
\text { organizations }\end{array}$} & SDG3 & Ensure healthy lives and promote well-being for all at all ages \\
\hline & & SDG4 & $\begin{array}{c}\text { Ensure inclusive and equitable quality education and promote lifelong learning } \\
\text { opportunities for all }\end{array}$ \\
\hline & & SDG5 & Achieve gender equality and empower all women and girls \\
\hline & & SDG9 & $\begin{array}{l}\text { Build resilient infrastructure, promote inclusive and sustainable } \\
\text { industrialization and foster innovation }\end{array}$ \\
\hline & & SDG11 & Make cities and human settlements inclusive, safe, resilient and sustainable \\
\hline & & SDG16 & $\begin{array}{l}\text { Promote peaceful and inclusive societies for sustainable development, provide } \\
\text { access to justice for all and build effective, accountable and inclusive institutions } \\
\text { at all levels }\end{array}$ \\
\hline & & SDG17 & $\begin{array}{l}\text { Strengthen the means of implementation and revitalize the Global Partnership } \\
\text { for Sustainable Development }\end{array}$ \\
\hline \multirow[b]{2}{*}{ Criterion 5} & \multirow[b]{2}{*}{$\begin{array}{l}\text { Landscapes and } \\
\text { seascapes features }\end{array}$} & SDG6 & Ensure availability and sustainable management of water and sanitation for all \\
\hline & & SDG15 & $\begin{array}{c}\text { Protect, restore and promote sustainable use of terrestrial ecosystems, } \\
\text { sustainably manage forests, combat desertification, halt and reverse land } \\
\text { degradation and halt biodiversity loss }\end{array}$ \\
\hline
\end{tabular}

Figure 1. Correlation between Globally Important Agricultural Heritage Systems (GIAHS) selection criteria and 17 SDGs.

According to the Beijing Declaration on Sustainable Development issued at the 7th Asia-Europe Summit in October 2008, three indicators - economic development, social progress and environmental protection-have been identified as the three pillars of sustainable development. Therefore, to comprehensively evaluate the sustainable development potential of GIAHS on the basis of the UN SDGs, this study matches the five selection criteria with the SDGs and integrates them into three evaluation dimensions: economic, social and environmental.

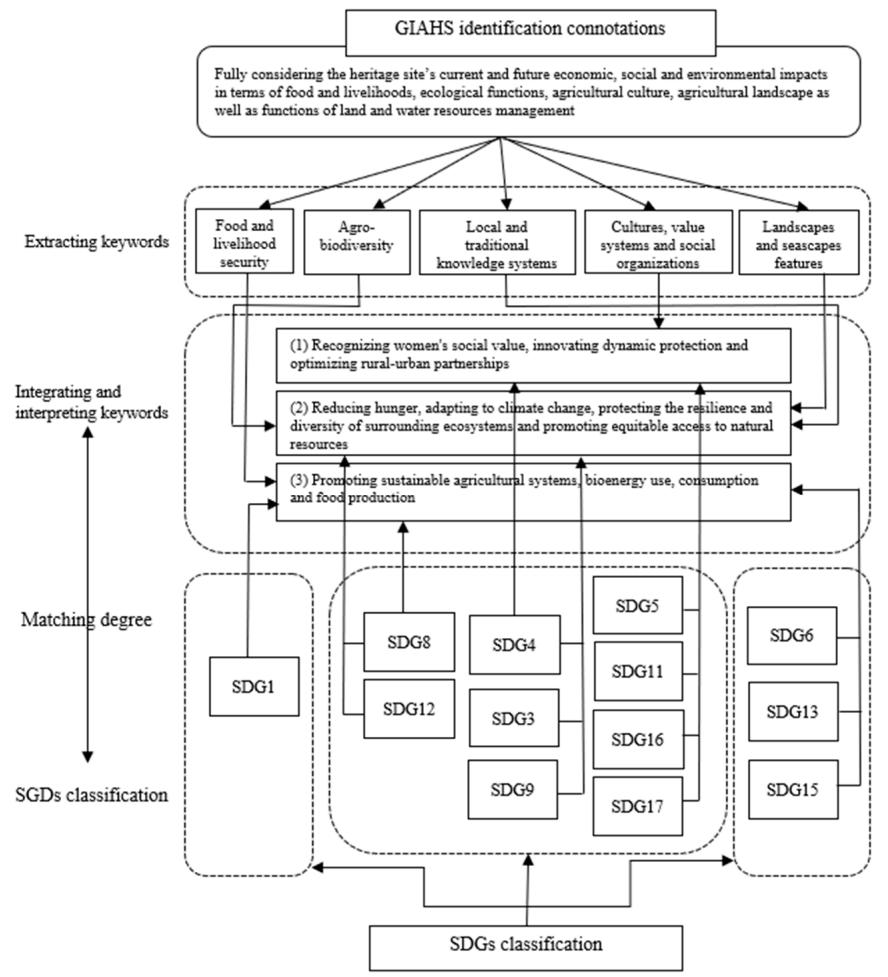

Figure 2. Interpretation of the matching degree between the SDGs and GIAHS identification connotations. 


\subsection{Establishment of the Evaluation Index System}

\subsubsection{Process and Basic Principles of the Establishment of the Evaluation Index System}

The GIAHS evaluation system is a methodology based on quantitative parameters for the evaluation and management of GIAHS sites, and its validation needs the participation of the stakeholders in this field or multidisciplinary surveys by experts [21,22].

GIAHS plays an important role in conserving biodiversity, promoting social organization and improving ecological and environmental quality. Therefore, the establishment of the GIAHS evaluation index system should follow several principles.

Objectivity. The objectivity of the evaluation index system determines the credibility of the results. Therefore, the establishment of the system should objectively reflect the development of GIAHS sites, and be based on the UN SDGs to form a systematic and hierarchical framework where the meanings of the indices should be clear and reflect facts.

Comprehensiveness. The idea of sustainable development involves social, economic and environmental factors, thus the establishment of the GIAHS evaluation index system should also be comprehensive and consider these aspects. Based on the UN SDGs, the system should take the holistic development strategy of "economic growth, social inclusion and environmental protection" into account, covering economic, social and environmental aspects.

Operability. Operability means that it is possible to use the evaluation index system to make calculation. Therefore, the expressions of the indices should be clear in terms of time interval and spatial scope, with concise and unambiguous meanings. The statistics of the indices should have scientific methods and fixed channels, so that the data are easily accessible and quantifiable, the measurement methods are accurate and standardized, and the evaluation results are comparable. The selection of three elements of economy, society and environment is based on the Driving force-State-Response (DSR) framework model of sustainable development. "Driving force" is human activities, processes and ways that have an impact on sustainable development, that is, environmental problems. "State", namely the state of sustainable development, means changes caused by various human activities such as socio-economic ones. "Response" refers to the choice and reflection of the changing state of sustainable development, that is, social system [23].

\subsubsection{Selection and Determination of the Evaluation Indices}

The SDGs involve 232 indices, and each index is still being refined. With reference to the practices of Chinese scholars $[24,25]$, this paper divides these indices into three types: the first type has clear definitions, scientific calculation methods and readily available statistics; the second type has clear definitions and exact calculation methods, but no available statistics; the third type is unclear in terms of definition, method and data, and therefore cannot be evaluated and calculated. Finally, the GIAHS evaluation index system is developed based on the UN SDGs and indices. The evaluation indices are identified in two steps as follows.

(1) Preliminary selection. This step solicits the opinions of 10 specialists through expert scoring method. 5 professors in the fields related to GIAHS, agricultural economics and sustainable development from domestic universities and 5 Chinese government or agency officials engaged in GIAHS declaration, monitoring, evaluation and subsequent sustainable management are selected. They have formed a team of experts (including 5 professors, 3 associate professors or associate research fellows and 2 high-level government officials) and scored the matching degree of 232 indices on a scale of 1 to 5 . According to the 5-point Likert scale, 5 points mean "extremely matching", 4 points "very matching", 3 points "obviously matching", 2 points "slightly matching" and 1 point "not matching". Based on the data collected and sorted out, the single index of which the total score made by 10 experts exceeds 40 is defined as a highly matching index (when 10 experts all think the index is very matching, it will acquire 40 points, so the boundary line is set as 40 ). When the total score of a single index is between 20 and 40 , it is defined as a generally matching one. If the total score is less than 20 , the index is defined as a low matching one 
(since the 10 experts all think the matching degree is low, the index will acquire a total of 20 scores which is set as the boundary line). According to this standard, 25 highly matching indices, 83 generally matching ones and 124 low matching ones are finally obtained. Then, a secondary selection is carried out in these 25 indices to make the types of industry as well as the spatial and temporal scope of the indices more concrete and localized.

(2) Secondary selection. According to the type and range of first-hand data available in GIAHS field study and monitoring as well as the distribution of comprehensive scores, 12 evaluation indices are selected and included into the GIAHS sustainability evaluation index system. Through further classification and integration, the four-level system is established. The first is the goal level, namely, the sustainable development goal of GIAHS sites. The second is the orientation level. As the 2030 Agenda for Sustainable Development emphasizes the strategic development goal of balancing economic growth, social inclusion and environmental sustainability, this paper also divides this level into three orientations of economic, social and environmental sustainability. The third is the indicator level, which distinguishes the various aspects under the orientation level. For example, economic and social sustainability are mainly reflected in the economic contribution of agriculture and social equity, respectively, and environmental sustainability has three indicator levels: environmental protection, ecological resources and disaster resilience. The fourth is the index level which consists of the direct indices for measuring the development effect of GIAHS.

As shown in Table 1, economic sustainability is mainly reflected in the contribution of GIAHS to local economy, including the proportion of the population living below the national poverty line, the annual growth rate of per capita GDP in GIAHS sites and the growth rate of GDP directly due to GIAHS. Social sustainability, mainly shown in social equity, is used to evaluate the cultural consciousness, female equity and sustainable development idea in heritage sites, and serves as an important measure of the sustainability of local social organizations. Environmental sustainability is mainly reflected in environmental protection, ecological resources and disaster resilience. Protecting environment is necessary for the sustainable development of heritage sites. Ecological resources demonstrate the balance of the local ecosystem. Disaster resilience directly affects the natural and social environment. The more resilient a GIAHS site is, the more sustainable it will be.

Table 1. Globally Important Agricultural Heritage Systems (GIAHS) evaluation index system based on the UN SDGs.

\begin{tabular}{|c|c|c|c|}
\hline Goal Level & Orientation Level & Indicator Level & Index Level \\
\hline \multirow{12}{*}{$\begin{array}{c}\text { GIAHS } \\
\text { Evaluation (A) }\end{array}$} & \multirow{3}{*}{$\begin{array}{c}\text { Economic } \\
\text { sustainability (L1) }\end{array}$} & \multirow{3}{*}{$\begin{array}{c}\text { Economic } \\
\text { contribution (P1) }\end{array}$} & $\begin{array}{l}\text { Proportion of the population living below national poverty } \\
\text { line (Q1) }\end{array}$ \\
\hline & & & Annual growth rate of per capita GDP in GIAHS sites (Q2) \\
\hline & & & Growth rate of GDP directly due to GIAHS (Q3) \\
\hline & \multirow{3}{*}{$\begin{array}{l}\text { Social sustainability } \\
\text { (L2) }\end{array}$} & \multirow{3}{*}{ Social equality (P2) } & Proportion of female contributors in GIAHS sites (Q4) \\
\hline & & & Proportion of females who own a mobile phone (Q5) \\
\hline & & & Proportion of GIAHS workforce (5-17 years old) (Q6) \\
\hline & \multirow{6}{*}{$\begin{array}{l}\text { Environmental } \\
\text { sustainability } \\
\quad \text { (L3) }\end{array}$} & \multirow{3}{*}{$\begin{array}{l}\text { Environmental } \\
\text { protection (P3) }\end{array}$} & $\begin{array}{l}\text { Inputs into water and sanitation protection (e.g., integrated } \\
\text { water resources management, wastewater treatment, } \\
\text { rainwater collection, etc.) (Q7) }\end{array}$ \\
\hline & & & $\begin{array}{l}\text { Inputs into the conservation of world cultural and natural } \\
\text { heritage (Q8) }\end{array}$ \\
\hline & & & Land area where biodiversity is fully protected (Q9) \\
\hline & & \multirow{2}{*}{$\begin{array}{l}\text { Ecological } \\
\text { resources (P4) }\end{array}$} & $\begin{array}{l}\text { Area of important sites for regional terrestrial and } \\
\text { freshwater biodiversity (Q10) }\end{array}$ \\
\hline & & & Forest and grass coverage (Q11) \\
\hline & & $\begin{array}{l}\text { Disaster resilience } \\
\quad(\mathrm{P} 5)\end{array}$ & $\begin{array}{l}\text { Direct economic losses caused by natural disasters or } \\
\text { accidents (Q12) }\end{array}$ \\
\hline
\end{tabular}




\subsubsection{Calculation of Index Weight}

The methods of determining the evaluation index weight include subjective weighting method, objective weighting method and comprehensive weighting method. Due to the restrictions on data collection in GIAHS sites, this paper combines the AHP with Delphi method to determine the index weight. It is assumed that the final evaluation goal is A and the index set is $\mathbf{L}=\left\{l_{1} l_{2} l_{3} \ldots \ldots l_{n}\right\}$, then the judgment matrix $\mathbf{P}(\mathbf{A}-\mathbf{L})$ is

$$
\mathbf{P}=\left[\begin{array}{ccc}
l_{11} & \ldots & l_{1 n} \\
\vdots & \ddots & \vdots \\
l_{1 n} & \ldots & l_{n n}
\end{array}\right]
$$

$l_{i j}$ indicates the relative importance of the factors, and the values are shown in Table 2.

Table 2. A-L judgement matrix and its meaning.

\begin{tabular}{cc}
\hline Value of $l$ & Meaning \\
\hline 1 & $l_{i}$ and $l_{j}$ are equally important \\
3 & $l_{i}$ is slightly more important than $l_{j}$ \\
5 & $l_{i}$ is obviously more important than $l_{j}$ \\
7 & $l_{i}$ is much more important than $l_{j}$ \\
$2,4,6,8$ & $l_{i}$ is very important comparing to $l_{j}$ \\
$l_{i j}=1 / l_{i j}$ & between $1-3,3-5,5-7$ and $7-9$, respectively, \\
\hline
\end{tabular}

Note: the definition of the comparison of importance. 1 . Equally important: score $1,\left(l_{i}-l_{j}\right) / l_{j}<10 \% 2$. Slightly important: score $3,10 \% \leq\left(l_{i}-l_{j}\right) / l_{j}<30 \% 3$. Obviously important: score $5,30 \% \leq\left(l_{i}-l_{j}\right) / l_{j}<50 \% 4$. Much more important: score $7,50 \% \leq\left(l_{i}-l_{j}\right) / l_{j}<70 \% 5$. Very important: score $9,\left(l_{i}-l_{j}\right) / l_{j} \geq 70 \%$.

GIAHS evaluation is considered as the overall goal, and the orientations of economic, social and ecological sustainability are L1, L2 and L3, respectively. Based on the assessment of the 10 specialists, the expert judgment matrix is shown in Table 3.

Table 3. A-L comparative judgement matrix.

\begin{tabular}{cccc}
\hline A & L $_{1}$ & L $_{2}$ & L $_{3}$ \\
\hline $\mathrm{L}_{1}$ & 1 & $\frac{1}{2}$ & $\frac{1}{3}$ \\
$\mathrm{~L}_{2}$ & 2 & 1 & $\frac{1}{2}$ \\
$\mathrm{~L}_{3}$ & 3 & 2 & 1 \\
\hline
\end{tabular}

By calculation, the eigenvectors $\mathbf{W}$ (ranking weights of factors) of the above matrix are $[0.16,0.30,0.54]$. Since the results of the judgment matrix are highly subjective, it is impossible to determine whether the matrix obtained from calculation has consistency or not. AHP is effective only when the judgment matrix has complete consistency and satisfactory consistency [26]. Therefore, the consistency test is conducted and the test formula is:

$$
\mathrm{CR}=\frac{C I}{R I}
$$

$\mathrm{CR}$ indicates the consistency ratio. When it is less than 0.10 , the judgment matrix is usually considered to have acceptable consistency, otherwise it needs to be revised. CI means the general consistency index, and RI shown in Table 4 is the average random consistency index.

$$
\mathrm{CI}=\frac{\lambda_{\max }-n}{\mathrm{n}-1}
$$

$\mathrm{n}$ is the order of the judgment matrix, and $\lambda_{\max }$ is its maximum eigenvalue. When CR is less than 0.1 , the judgement matrix has consistency, otherwise it needs to be re-judged. $\lambda_{\max }$ should be calculated in five steps: 
(1) Calculating $m_{I}$, the product of the elements in each row of the matrix

$$
m_{I}=\prod_{j=1}^{n} b_{i j},(i=1,2 \cdots \cdots, n)
$$

(2) Calculating $\bar{W}_{i}$, the nth root of $m_{I}$ :

$$
\overline{W_{i}}=\sqrt[n]{M_{i}}
$$

(3) Regularizing the vectors:

$$
W_{i}=\frac{\overline{W_{i}}}{\sum_{j=1}^{n} W_{j}}
$$

(4) Calculating the eigenvector $W_{i}=\left[W_{1}, W_{2}, \ldots \ldots, W_{n}\right]^{\mathrm{T}}$, namely the weight of each index.

(5) Calculating $\lambda_{\max }$ :

$$
\lambda_{\max }=\sum_{i=1}^{n} \frac{(A W)_{i}}{n W i}
$$

Table 4. Random consistency parameters.

\begin{tabular}{cccccccccc}
\hline Order (n) & $\mathbf{1}$ & $\mathbf{2}$ & $\mathbf{3}$ & $\mathbf{4}$ & $\mathbf{5}$ & $\mathbf{6}$ & $\mathbf{7}$ & $\mathbf{8}$ & $\mathbf{9}$ \\
\hline $\mathrm{RI}$ & 0.00 & 0.00 & 0.58 & 0.90 & 1.12 & 1.24 & 1.32 & 1.41 & 1.45 \\
\hline
\end{tabular}

Matlab can be used to calculate the ranking of index weights at each level and ranking

\begin{tabular}{|c|c|c|c|c|c|c|}
\hline Goal Level & Orientation Level & Weight & Indicator Level & Weight & Index Level & Weight \\
\hline \multirow{12}{*}{$\begin{array}{l}\text { GIAHS } \\
\text { Evaluation (A) }\end{array}$} & \multirow{3}{*}{$\begin{array}{c}\text { Economic } \\
\text { sustainability (L1) }\end{array}$} & \multirow{3}{*}{0.30} & \multirow{3}{*}{$\begin{array}{c}\text { Economic } \\
\text { contribution }(\mathrm{P} 1)\end{array}$} & \multirow{3}{*}{1.00} & $\begin{array}{c}\text { Proportion of the population living below national } \\
\text { poverty line (Q1) }\end{array}$ & 0.45 \\
\hline & & & & & $\begin{array}{l}\text { Annual growth rate of per capita GDP in GIAHS } \\
\text { sites (Q2) }\end{array}$ & 0.23 \\
\hline & & & & & Growth rate of GDP directly due to GIAHS (Q3) & 0.32 \\
\hline & \multirow{3}{*}{$\begin{array}{l}\text { Social sustainability } \\
\text { (L2) }\end{array}$} & \multirow{3}{*}{0.16} & \multirow{3}{*}{ Social equality (P2) } & \multirow{3}{*}{1.00} & Proportion of female contributors in GIAHS sites (Q4) & 0.55 \\
\hline & & & & & Proportion of females who own a mobile phone (Q5) & 0.18 \\
\hline & & & & & Proportion of GIAHS workforce (5-17 years old) (Q6) & 0.27 \\
\hline & \multirow{6}{*}{$\begin{array}{l}\text { Environmental } \\
\text { sustainability(L3) }\end{array}$} & \multirow{6}{*}{0.54} & \multirow{3}{*}{$\begin{array}{l}\text { Environmental } \\
\text { protection (P3) }\end{array}$} & \multirow{3}{*}{0.30} & $\begin{array}{l}\text { Inputs into water and sanitation protection (e.g., } \\
\text { integrated water resources management, wastewater } \\
\text { treatment, rainwater collection, etc.) (Q7) }\end{array}$ & 0.20 \\
\hline & & & & & $\begin{array}{c}\text { Inputs into the conservation of world cultural and } \\
\text { natural heritage (Q8) }\end{array}$ & 0.47 \\
\hline & & & & & Land area where biodiversity is fully protected (Q9) & 0.33 \\
\hline & & & \multirow{2}{*}{$\begin{array}{l}\text { Ecological resources } \\
\text { (P4) }\end{array}$} & \multirow{2}{*}{0.54} & $\begin{array}{c}\text { Area of important sites for regional terrestrial and } \\
\text { freshwater biodiversity }(\mathrm{Q} 10)\end{array}$ & 0.24 \\
\hline & & & & & Forest and grass coverage (Q11) & 0.76 \\
\hline & & & $\begin{array}{l}\text { Disaster resilience } \\
\text { (P5) }\end{array}$ & 0.16 & $\begin{array}{l}\text { Direct economic losses caused by natural disasters or } \\
\text { accidents (Q12) }\end{array}$ & 1.00 \\
\hline
\end{tabular}
of all index weights, and the final GIAHS evaluation system is obtained and shown in Table 5.

Table 5. GIAHS evaluation index system based on UN SDGs.

The index data in the system should be annual statistics for GIAHS sites.

\section{Case Study: GIAHS Sustainability Evaluation of the Kuaijishan Ancient Chinese Torreya Community in Shaoxing City, Zhejiang Province}

\subsection{Overview of the Research Area}

The Kuaijishan Ancient Chinese Torreya Community in Shaoxing City (Figure 3) is a unique mountain use system with a variety of functions, including economic function, biodiversity conservation, agricultural landscape preservation, agricultural cultural inher- 
itance and ecological protection. The GIAHS site is located at 59 administrative villages in 12 townships in Keqiao district, Zhuji city and Shengzhou city, with a total area of 402 square kilometers. According to our survey, there are 105,000 large Chinese Torreya trees in this area, of which 72,000 are over 100 years old and 4500 are over 1000 years old. More than 2000 years ago, the ancestors in Shaoxing selected and grafted the wild Chinese Torreya trees to cultivate this quality variety [27]. Due to artificial grafting, many of the existing ancient Chinese Torreya trees have visible scars in the shape of bull's leg at the base. The oldest one is 1567 years old (till 2012) and stands $18 \mathrm{~m}$ tall, similar to a giant umbrella [28]. Despite being a thousand years old, these ancient trees are still fruitful, making them a rare "living specimen" of ancient breeding and grafting techniques.

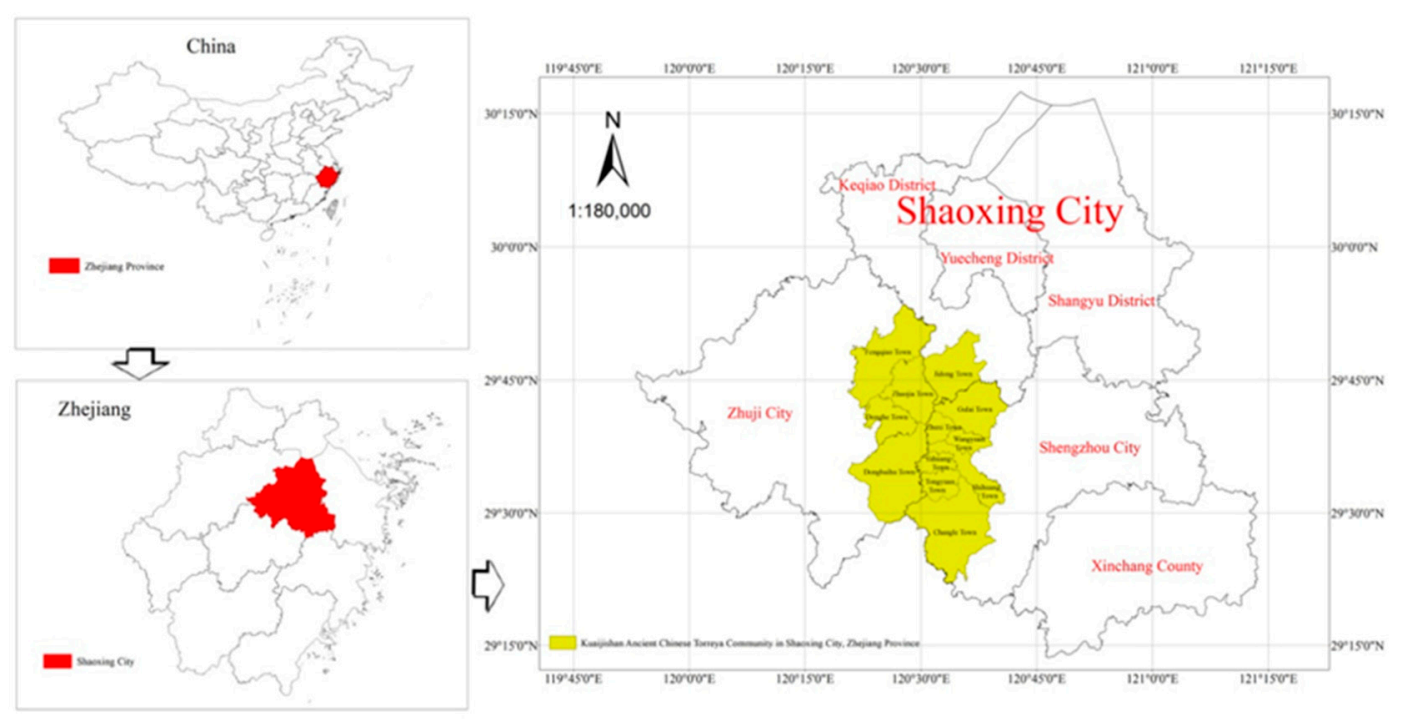

Figure 3. Location of the Kuaijishan Ancient Chinese Torreya Community.

The ancestors in Shaoxing built terraced fields (fish-scale pits) on steep-sloped hills to plant Chinese Torreya trees, with tea, miscellaneous grains and vegetables intercropped under the trees. The compound management system of Chinese Torreya trees, terraces and undergrowth crops constitutes a unique system of steep-slope hills featuring water and soil conservation and high production [29]. The evergreen and beautiful ancient Chinese Torreya trees form a spectacular landscape merged with the traditional villages, abundant streams and mountains. From ancient times to the present, prose, poetry and art works have been produced in praise of Chinese Torreya, and there have been a variety of related rituals and festivals [30]. This area is listed as a cultural relic protection site in Zhejiang Province, and there are two provincial nature reserves, one national forest park and two provincial forest parks in the area.

\subsection{Evaluation Methods}

\subsubsection{Data Sources}

The research sites were Shiao, Zhan'ao and Chencun villages in Jiandong Town, Keqiao District, as well as Lvao and Yushu villages in Gulai Town, Shengzhou City which are located in the core area of the GIAHS site. In order to facilitate the collection of empirical data, the research was conducted in November when farmers had relatively sufficient time as they had already finished harvesting and selling the green fruits of Chinese Torreya. The survey had two parts: a questionnaire for the farmers and a discussion with the government staff. Considering the literacy and cognitive level of the farmers, and to ensure the response rate and effectiveness of the questionnaires, the researchers conducted household surveys to ask the respondents questions and record their answers faithfully, and interview served as a supplement. A total of 180 questionnaires were distributed to the farmers, of which 172 were valid. 


\subsubsection{Data Standardization}

To facilitate comparison, the data for each index of this GIAHS site were expressed as percentages in this paper, and the index data were linearly transformed to standard values between 0 and 100, with the formula for data adjustment in the range of 0 to 100 being [31]

$$
x^{\prime}=\frac{x-\operatorname{lower}(x)}{\operatorname{upper}(x)-\operatorname{lower}(x)} * 100
$$

$x$ is the original data with upper and lower values indicating best and worst performance, respectively, and $x^{\prime}$ is the recalibrated standard value with a threshold referring to the report of the UN Sustainable Development Solutions Network. Values above 100 are still equivalent to 100, and negative values are equivalent to 0 , as shown in Table 6 .

Table 6. Actual and reference values for standardization.

\begin{tabular}{ccc}
\hline Index & Data & Standard Values (\%) \\
\hline $\begin{array}{c}\text { Proportion of the population living below national } \\
\text { poverty line (Q1) }\end{array}$ & $0 \%$ & 100 \\
\hline Annual growth rate of per capita GDP in GIAHS sites (Q2) & $42 \%$ & 40 \\
\hline Growth rate of GDP directly due to GIAHS (Q3) & $88 \%$ & 55 \\
\hline Proportion of female contributors in GIAHS sites (Q4) & $52 \%$ & 100 \\
\hline Proportion of females who own a mobile phone (Q5) & $100 \%$ & 100 \\
\hline $\begin{array}{c}\text { Proportion of GIAHS workforce (5-17 years old) (Q6) } \\
\text { Inputs into water and sanitation protection (e.g., }\end{array}$ & $0 \%$ & 8 \\
\hline $\begin{array}{c}\text { integrated water resources management, wastewater } \\
\text { treatment, rainwater collection, etc.) (Q7) }\end{array}$ & $6.40 \%$ & 50 \\
\hline $\begin{array}{c}\text { Inputs into the conservation of world cultural and natural } \\
\text { heritage (Q8) }\end{array}$ & $47.60 \%$ & 35 \\
\hline $\begin{array}{c}\text { Land area where biodiversity is fully protected (Q9) } \\
\text { Area of important sites for regional terrestrial and } \\
\text { freshwater biodiversity (Q10) }\end{array}$ & $63.60 \%$ & 88 \\
\hline Forest and grass coverage (Q11) & $36.60 \%$ & 90 \\
\hline $\begin{array}{c}\text { Direct economic losses caused by natural disasters or } \\
\text { accidents (Q12) }\end{array}$ & $83 \%$ & $0.35 \%$ \\
\hline
\end{tabular}

\subsubsection{Evaluation Function Model}

The GIAHS evaluation index system in this paper can assess sustainability using a comprehensive method with the following function.

$$
\mathrm{A}=\sum_{i=1}^{m}\left(\sum_{j=1}^{n} Q_{I} * G_{i}\right) W_{i}
$$

A is the comprehensive evaluation score, $Q_{I}$ is the score of a single index, $G_{i}$ is the weight of a single index at its level, and $W_{i}$ is the index weight of the three orientation levels.

\subsection{Evaluation Results}

According to Formula (9), the comprehensive evaluation score of the Kuaijishan Ancient Chinese Torreya Community is 77.90 points, of which economic, social and environmental sustainability scores $88.27,86.12$ and 69.71 points respectively, showing a descending trend (see Table 7). 
Table 7. Evaluation scores for the GIAHS site of the Kuaijishan Ancient Chinese Torreya Community (\%).

\begin{tabular}{|c|c|c|c|c|c|c|}
\hline Goal Level & $\begin{array}{l}\text { Orientation } \\
\text { Level }\end{array}$ & Score & $\begin{array}{l}\text { Indicator } \\
\text { Level }\end{array}$ & Score & Index Level & Score \\
\hline \multirow{12}{*}{$\begin{array}{l}\text { GIAHS } \\
\text { Evaluation } \\
\text { Score } \\
77.90\end{array}$} & \multirow{3}{*}{$\begin{array}{c}\text { Economic } \\
\text { sustainability }\end{array}$} & \multirow{3}{*}{88.27} & \multirow{3}{*}{$\begin{array}{l}\text { Economic } \\
\text { contribution }\end{array}$} & \multirow{3}{*}{81.40} & $\begin{array}{l}\text { Proportion of the population living } \\
\text { below national poverty line (Q1) }\end{array}$ & 45.00 \\
\hline & & & & & $\begin{array}{c}\text { Annual growth rate of per capita GDP } \\
\text { in GIAHS sites (Q2) }\end{array}$ & 9.20 \\
\hline & & & & & $\begin{array}{l}\text { Growth rate of GDP directly due to } \\
\text { GIAHS (Q3) }\end{array}$ & 27.20 \\
\hline & \multirow{3}{*}{$\begin{array}{c}\text { Social } \\
\text { sustainability }\end{array}$} & \multirow{3}{*}{86.12} & \multirow{3}{*}{$\begin{array}{l}\text { Social } \\
\text { equality }\end{array}$} & \multirow{3}{*}{75.80} & $\begin{array}{l}\text { Proportion of female contributors in } \\
\text { GIAHS sites (Q4) }\end{array}$ & 30.80 \\
\hline & & & & & $\begin{array}{c}\text { Proportion of females who own a } \\
\text { mobile phone (Q5) }\end{array}$ & 18.00 \\
\hline & & & & & $\begin{array}{l}\text { Proportion of GIAHS workforce } \\
\text { (5-17 years old) (Q6) }\end{array}$ & 27.00 \\
\hline & \multirow{6}{*}{$\begin{array}{l}\text { Environmental } \\
\text { sustainability }\end{array}$} & \multirow{6}{*}{69.71} & \multirow{3}{*}{$\begin{array}{l}\text { Environmental } \\
\text { protection }\end{array}$} & \multirow[t]{3}{*}{48.86} & $\begin{array}{l}\text { Inputs into the activities related to } \\
\text { water and sanitation protection (e.g., } \\
\text { integrated water resources } \\
\text { management, wastewater treatment, } \\
\text { rainwater collection, etc.) (Q7) }\end{array}$ & 1.60 \\
\hline & & & & & $\begin{array}{l}\text { Inputs into the conservation of world } \\
\text { cultural and natural heritage (Q8) }\end{array}$ & 23.50 \\
\hline & & & & & $\begin{array}{l}\text { Land area where biodiversity is fully } \\
\text { protected (Q9) }\end{array}$ & 23.76 \\
\hline & & & \multirow[t]{2}{*}{$\begin{array}{l}\text { Ecological } \\
\text { resources }\end{array}$} & \multirow[t]{2}{*}{75.28} & $\begin{array}{l}\text { Area of important sites for regional } \\
\text { terrestrial and freshwater biodiversity } \\
\text { (Q10) }\end{array}$ & 8.40 \\
\hline & & & & & Forest and grass coverage (Q11) & 66.88 \\
\hline & & & $\begin{array}{l}\text { Disaster } \\
\text { resilience }\end{array}$ & 90.00 & $\begin{array}{l}\text { Direct economic losses caused by } \\
\text { natural disasters or accidents (Q12) }\end{array}$ & 90 \\
\hline
\end{tabular}

In terms of economic sustainability, there is no population living below the national poverty line in this GIAHS site, and the growth rate of GDP directly due to GIAHS is relatively high, indicating that this GIAHS site has a good economic potential and thus can serve as an important guarantee for local economy. As for social sustainability, the Ancient Chinese Torreya Community provides equal employment opportunities for local workforce of different ages. Women are treated more equally in terms of their living standard and social interaction, although their contribution to heritage conservation is relatively low. When it comes to environmental sustainability, investment in environmental protection is insufficient, particularly in relation to water and sanitation protection. The low score for area of sites which are important for regional terrestrial and freshwater biodiversity suggests that efforts to set up dedicated areas for biodiversity conservation also seem to be inadequate. However, the heritage system that have been developed over a long period of time to date shows its outstanding resilience to disasters.

In the future, the GIAHS site of the Kuaijishan Ancient Chinese Torreya Community will increase its efforts to protect the ecological environment and place ecological protection in a prominent position in the GIAHS conservation to sustain the existing biological resources and biodiversity. More efforts should also be made to monitor the dynamics of the region's terrestrial and freshwater biodiversity and issue timely warnings to minimize the potential loss of ecological resources or reduction of biodiversity. 


\section{Discussion}

This paper matches the 232 indices of the UN SDGs with the connotations of FAOGIAHS certification as a theoretical basis for the GIAHS sustainability evaluation index system, making the system scientific and sound (see Figure 1). First, GIAHS was set up to achieve the SDGs, which is the primary reason why this paper bases the GIAHS assessment system on the SDGs. In 2002, the GIAHS Dynamic Conservation and Adaptive Management Project was initiated by the FAO to establish a globally recognized system which was aimed to protect GIAHS and related landscape, biodiversity, knowledge and culture, as well as to provide technical support for sustainable agricultural and rural development. GIAHS have become an important contributor to the UN SDGs and the Convention on Biological Diversity. In September 2015, the UN member states adopted the 2030 Agenda for Sustainable Development and 17 SDGs. Food and agriculture are key to achieving all the SDGs, and rural development and investments in agriculture, namely crops, livestock, forestry, fisheries and aquaculture, are powerful tools for eradicating poverty and hunger and achieving sustainable development. China's Rice Fish Culture in Qingtian County, Zhejiang Province, a GIAHS site selected in 2005, has greatly increased the rice price and tourism income after a decade [32]. Some of the GIAHS sites in China have achieved several SDGs by using new technologies and cooperating with private enterprises to promote local products and employment [33]. Secondly, there is a correlation between the GIAHS selection criteria and SDGs. According to the official FAO-GIAHS report, there are five identification criteria for GIAHS sites, namely food and livelihood security, agro-biodiversity, local and traditional knowledge systems, cultures, value systems and social organizations as well as landscapes and seascapes features. As mentioned above, all of these officially designated criteria are closely linked to the UN SDGs, especially to SDGs 1, 2, 3, 5, 6, 7, 8, 9, 10, 12, 13, 14, 15 and 17 [4]. Therefore, the SDGs and their specific indices which are well matched with the connotations of GIAHS certification will guide the evaluation of GIAHS and make the indices more comprehensive and authoritative.

Some innovations have been made on the basis of previous research. Firstly, this paper selects and determines the evaluation indices through qualitative analysis, and then establishes the system through quantitative analysis. It is the first study in China to build a quantitative evaluation system for GIAHS based on the SDGs, combining and upgrading domestic and foreign research and applications of the SDGs. Secondly, the GIAHS evaluation index system in this paper follows the three principles of objectivity, comprehensiveness and operability, so that the meaning of the indices is concise and unambiguous. The data of the indices have scientific statistical methods and fixed statistical channels. The setting of indices has also taken into account many factors such as easy accessibility, quantifiability, accurate and standardized measurement methods and comparability of evaluation results, laying a foundation for the subsequent promotion and application of the evaluation system. Thirdly, this paper ensures the completeness of the evaluation indices by using AHP.

The GIAHS evaluation index system based on the UN SDGs aligns with the international focus on sustainable development and GIAHS. Based on the existing GIAHS evaluation systems, it further optimizes the indices by cutting the amount to facilitate statistics and selects indices that better reflect the core of the SDGs and GIAHS. Compared to the previous evaluation systems, the process of establishing this system is less influenced by subjective factors, such as the professional background of researchers. Even though this paper only takes the Kuaijishan Ancient Chinese Torreya as an example for the sustainability evaluation of GIAHS, the system is not only applicable to this heritage site, but also to many other sites in China and beyond. In the future, this evaluation index system can be popularized worldwide to compare the sustainability of GIAHS sites around the world and underpin the subsequent adjustment of their development models.

However, this paper has shortcomings in terms of indices and data. As the UN SDGs are a large and complicated evaluation system, it is difficult to directly convert and quantify the evaluation indices, and there are complex synergy and balance among them. Due to 
the restricted access to data, the paper excludes indices for which data are not available, which to some extent makes the indices less comprehensive. Different regions and types of industry determine the selection of different evaluation indices. The standardization and localization of the SDG indices and a unified evaluation system are the prerequisites for further application of the SDGs in GIAHS evaluation. More inputs should be devoted to statistical capacity building, and each SDG index data should be processed and disclosed by different departments to reduce the incompleteness of the evaluation due to missing data. In addition, this paper combines Delphi method with AHP for building the evaluation system, which is somewhat subjective. In the future, when more regions apply the SDGs to GIAHS evaluation or when more adequate data are obtained, a combination of subjective and objective methods can be used to calculate the weights of indices in the evaluation system. Meanwhile, the evaluation system will help build a transnational cooperation platform for the global scientific research and protection of GIAHS, promoting international exchanges and providing scientific basis for multidisciplinary analysis [34].

\section{Conclusions and Recommendations}

Based on the matching analysis of the 232 indices of the UN SDGs with FAO-GIAHS identification connotations, this paper shows the process and basic principles of establishing the evaluation index system in accordance with the international focus on sustainable development and existing FAO-GIAHS selection criteria system. The GIAHS sustainability evaluation index system that takes into account economic, social and environmental aspects and index weights are built through two selection processes and expert systematic assessment, which provides an objective methodological reference for evaluating the contribution of GIAHS to the achievement of the UN SDGs. Using this index system to evaluate the GIAHS sustainability of the Kuaijishan Ancient Chinese Torreya Community in Shaoxing City, Zhejiang Province shows that ecological sustainability is the shortcoming of GIAHS conservation. The protection of environment and biodiversity is particularly easy to be neglected.

Future GIAHS conservation should focus on the following aspects: (1) establishing GIAHS conservation implementation guidelines at the FAO and national levels, especially conservation action guidelines on environment and biodiversity; (2) strengthening regular GIAHS monitoring and assessment, and building a scientific monitoring and evaluation index system as well as supervision and management mechanism for GIAHS site conservation; (3) promoting science popularization of GIAHS conservation, and raising the awareness of the public, especially the elderly, women and other key protectors; (4) strengthening scientific research on GIAHS conservation and evaluation to provide scientific and technological support for GIAHS protection and its international comparison and exchange.

Author Contributions: Conceptualization, W.Z. and S.W.; methodology, W.Z. and H.L.; software, H.L.; validation, W.Z., S.W. and Y.Z.; formal analysis, R.A. and M.X.; investigation, H.Q., Y.L. and W.Z.; resources, W.Z.; data curation, W.Z. and H.L.; writing-original draft preparation, W.Z., H.L. and R.A.; writing-review and editing, W.Z., S.W., Y.Z. and M.X.; visualization, R.A., H.L. and H.Q.; supervision, W.Z. and Y.L.; project administration, S.W., Y.L. and H.Q.; funding acquisition, S.W., Y.L. and H.Q. All authors have read and agreed to the published version of the manuscript.

Funding: This paper was funded by Research on the Silk Road and Sino-Foreign Agricultural Exchange (grant number 16AZS005), a key project of the National Social Science Fund of China and Research on the Impact of Agricultural Heritage Conservation and Development on the Return of Labour Force (grant number SKCX2020004), an innovative project of the Fundamental Scientific Research Fund for Universities Affiliated to Central Government Departments.

Institutional Review Board Statement: Not applicable.

Informed Consent Statement: Not applicable. 
Data Availability Statement: The data presented in this study are available on request from the corresponding author. Since samples for the assessment are taken from surveys of local farmers, the data cannot be publicly available without their consent.

Conflicts of Interest: The authors declare no conflict of interest. The funders had no role in the design of the study; in the collection, analyses, or interpretation of data; in the writing of the manuscript, or in the decision to publish the results.

\section{References}

1. Raheem, U.A. Understanding the spatial context of sustainable urban health in Africa for the SDGs: Some lessons from the corridors of deprivation in Ilorin, Nigeria. Afr. Geogr. Rev. 2017, 36, 216-235. [CrossRef]

2. Barnett, C.; Parnell, S. Ideas, implementation and indicators: Epistemologies of the post-2015 urban agenda. Environ. Urban. 2016, 28, 87-98. [CrossRef]

3. Arslan, T.V.; Durak, S.; Aytac, D.O. Attaining SDG11: Can sustainability assessment tools be used for improved transformation of neighbourhoods in historic city centers? In Natural Resources Forum; Blackwell Publishing Ltd.: Oxford, UK, 2016; Volume 40, pp. 180-202.

4. Sachs, J.; Schmidt-Traub, G.; Kroll, C.; Durand-Delacre, D.; Teksoz, K. SDG Index and Dashboards-Global Report; Bertelsmann Stiftung and Sustainable Development Solutions Network (SDSN): New York, NY, USA, 2016.

5. Chen, J.; Peng, S.; Zhao, X.S.; Ge, Y.J.; Li, Z.L. Measuring regional progress towards SDGs by combining geospatial and statistical information. Acta Geod. Cartogr. Sin. 2019, 48, 473-479. (In Chinese)

6. Guan, T.; Xue, L. How the SDGs are implemented in different countries? China Popul. Resour. Environ. 2019, 29, 11-20. (In Chinese)

7. Sheryl, R.C.R.; Evonne, Y.; Aya, M.; Osamu, S. Enhancing Sustainability in Traditional Agriculture: Indicators for Monitoring the Conservation of Globally Important Agricultural Heritage Systems (GIAHS) in Japan. Sustainability. 2020, $12,5656$.

8. Zhang, Y.; Min, Q.; Zhang, C.; He, L.; Zhang, S.; Yang, L.; Tian, M.; Xiong, Y. Traditional culture as an important power for maintaining agricultural landscapes in cultural heritage sites: A case study of the Hani terraces. J. Cult. Herit. 2017, 25, 170-179. [CrossRef]

9. Sangbum, K. Systematic Survey and Monitoring Methods of Agricultural Heritage Systems in Korea; Center for Natural and Cultural Heritage, IGSNRR, CAS: Xinghua, China, 2014.

10. Min, Q.W.; Zhao, G.G.; Jiao, W.J. Progress of World Heritage Monitoring and Evaluation and Enlightenments to China's Agriculture Heritage Systems Management. World Agric. 2015, 11, 97-100, 255. (In Chinese)

11. Goodland, R. The concept of environmental sustainability. Annu. Rev. Ecol. Evol. Syst. 1995, 26, 1-24. [CrossRef]

12. Wang, P.L.; Gao, F.; Huang, C.L.; Song, X.Y.; Wang, B.; Wei, Y.Q.; Niu, Y.B. Progress on Sustainable City Assessment Index System for SDGs. Remote. Sens. Technol. Appl. 2018, 33, 784-789.

13. FAO. GIAHS Globally Important Agricultural Heritage System. Selection Criteria and Action Plan [EB/OL]. Available online: http:/ / www.fao.org/giahs/become-a-giahs/selection-criteriaand-action-plan/en/ (accessed on 23 April 2021).

14. Kemkes, R.J. The role of natural capital in sustaining livelihoods in remote mountainous regions: The case of Upper Svaneti, Republic of Georgia. Ecol. Econ. 2015, 117, 22-31. [CrossRef]

15. Veldhuizen, L.J.L.; Giller, K.E.; Oosterveer, P.; Brouwer, I.D.; Janssen, S.; van Zanten, H.H.E.; Slingerland, M.A. The Missing Middle: Connected action on agriculture and nutrition across global, national and local levels to achieve Sustainable Development Goal 2. Glob. Food Sec. 2020, 24, 100336. [CrossRef]

16. Bjegovic-Mikanovic, V.; Abousbie, Z.A.S.; Breckenkamp, J.; Wenzel, H.; Broniatowski, R.; Nelson, C.; Vukovic, D.; Laaser, U. A gap analysis of SDG 3 and MDG 4/5mortality health targets in the six Arabic countries of North Africa: Egypt, Libya, Tunisia, Algeria, Morocco, and Mauritania. Libyan J. Med. 2019, 14, 1607698. [CrossRef] [PubMed]

17. Lankoski, J.; Ollikainen, M. Agri-environmental externalities: A framework for designing targeted policies. Eur. Rev. Agric. Econ. 2003, 30, 51-75. [CrossRef]

18. Yuan, J.J.; Lv, Y.L.; He, G.Z. Marine Sustainable Development Goals and Marine and Coastal Ecosystem Management. Sheng Tai Хue Bao 2017, 37, 8139-8147. (In Chinese)

19. Wu, Z.Q.; Lv, H. Reflection on European Green Capital Award and Urban Sustainability Assessment. Shanghai Urban Plan. Rev. 2012, 6, 81-84. (In Chinese)

20. Chen, J.; Ren, H.R.; Geng, W.; Peng, S.; Ye, F.H. Quantitative Measurement and Monitoring Sustainable Development Goals (SDGs) with Geospatial Information. Geomat. World 2018, 25, 1-7. (In Chinese)

21. Torres-Delgado, A.; Saarinen, J. Using indicators to assess sustainable tourism development: A review. Tour. Geogr. 2017, 26, 803-814. [CrossRef]

22. Xiao, H.; Wang, X.Y.; Chen, J.Q.; Jin, X.F. Exploring data demand for monitoring sustainable development goals issued by United Nation. China Popul. Resour. Environ. 2018, 28, 1-4. (In Chinese)

23. Zhao, L.F. The strategy for Sustainable Development in China. J. Cent. Univ. Financ. Econ. 2002, 1, 18-21. (In Chinese)

24. Fan, B.B. Construction of Evaluation Index System for Sustainable Development of Rural Tourism Resources. Trans. Chin. Soc. Agric. Eng. 2018, 8, 148-151. (In Chinese)

25. Fang, L.X.; Wu, X.R.; Zhang, Y. The National Sustainable Development Strategies of the EU countries: Latitude Evaluation and Policy Revelation. Peace Dev. 2017, 6, 97-107, 128. (In Chinese) 
26. $\mathrm{Wu}, \mathrm{J}$. The Establishment and Evaluation of the Index System of Tourism Sustainable Development: A Case Study of Qingdao. Inq. Econ. Issues 2013, 10, 64-70. (In Chinese)

27. Min, Q.W.; Zhang, X.J. The Legend of Ancient Chinese Torreya: Interpretation of the GIAHS Site of Shaoxing Kuaijishan Chinese Torreya in Zhejiang Province. World Herit. 2013, 5, 28-29.

28. Yang, G.M.; Wang, B.; Bai, Y.Y. Approaches to Dynamic Protection on Traditional Agriculture with Ancient Torreya Grandis in Kuaiji Mountain. Hunan Agric. Sci. 2014, 22, 59-61. (In Chinese)

29. Gu, Y.Q.; Hui, F.P. The Research on the Historical Culture of the Ancient Torreya Grandis in Kuaiji Mountain and its Heritage Tourism. Agric. Hist. China 2019, 38, 123-131. (In Chinese)

30. Kuaijishan Ancient Chinese Torreya Community Protection Administration in Shaoxing City. The Globally Important Agricultural Heritage Systems Site of the Kuaijishan Ancient Chinese Torreya Community in Shaoxing City, Zhejiang Province. J. China Agric. Uni. Soc. Sci. 2017, 34, 1. (In Chinese)

31. Liu, T.T. Research on Evaluation of Rural Vacation Sustainable Development: A Case of Yuanjia Village in Shaanxi Province. Master's Thesis, Xi'an International Studies University, Xi'an, China, 2018.

32. Su, Y.Y.; Wang, Y.; Sun, Y.H.; Min, Q.W.; Jiao, W.J. Relationship between tourists' environmental responsibility behavior and food preference in agricultural heritage sites: A case study of Qingtian Rice-fish Culture System. Chin. J. Eco-Agric. 2020, 28, 1414-1424. (In Chinese)

33. Ma, Z.B. Influence of Agricultural Labor Force Transfer on Protection and Inheritance of Agricultural Heritage. Agric. Archaeol. 2019, 1, 251-259. (In Chinese)

34. Li, H.Y.; Min, Q.W.; Liu, M.C.; Zhang, B.T. Globally Important Agricultural Cultural Heritage Systems and Sustainable Society: Summary and Prospect of the Fifth East Asian Symposium on Agricultural Cultural Heritage. J. China Agric. Uni. Soc. Sci. 2019, 36, 131-136. (In Chinese) 